\title{
Comparative analysis of phenolic compounds in four taxa of Erigeron acris s. I. (Asteraceae)
}

\author{
Edyta Nalewajko-Sieliwoniuk ${ }^{1}$ (D) - Artur Pliszko ${ }^{2} \cdot$ Jolanta Nazaruk $^{3} \cdot$ Eliza Barszczewska $^{1} \cdot$ Weronika Pukszta $^{1}$
}

Received: 27 March 2019 / Accepted: 22 July 2019/Published online: 5 August 2019

(C) The Author(s) 2019

\begin{abstract}
The aim of the present work was to investigate and compare the content of phenolic compounds in four taxa of Erigeron acris $\mathrm{L}$. s. 1.: E. acris (EAA), E. acris subsp. droebachiensis (O.F. Müll.) Arcang. (EAD), E. acris subsp. serotinus (Weihe) Greuter (EAS) and E. $\times$ huelsenii Vatke $(\mathrm{EH})$, a hybrid between E. acris and E. canadensis L. The total flavonoid content was determined by Christ-Müller method and the total phenolic acid content was determined by the method utilizing Arnov's reagent. The method using ultra high performance liquid chromatography with photodiode array detection (UHPLC-PDA) was applied for the separation, identification and quantification of nine phenolic compounds (protocatechuic acid, chlorogenic acid, caffeic acid, $6^{\prime}$ - $O$-caffeoylerigeroside, scutellarein-7- $O$ - $\beta$-D-glucuronide, quercetin 3-O-glucoside, 4,5-dicaffeoylquinic acid, quercetin and luteolin) in the aerial parts of $E$. acris s. 1. The chromatographic separation was carried out using a BEH $\mathrm{C}_{18}$ column packed with $1.7-\mu \mathrm{m}$ particles and gradient elution with a mobile phase of water and methanol, both containing $0.02 \%(\mathrm{v} / \mathrm{v})$ trifluoroacetic acid. The four investigated taxa of E. acris s. 1. differed in the composition and the content of phenolic compounds. The main substances determined in the methanolic herbal extracts were: scutellarein-7-O- $\beta$-D-glucuronide (EAA, EAS, EAD and EH), $6^{\prime}$ $O$-caffeoylerigeroside (EAA, EAD and EH) and chlorogenic acid (EAS and EH). Moreover, the results indicated that five of the nine tested compounds were found in all investigated extracts from herbs of $E$. acris $\mathrm{s}$. 1. Two of them (6'-O-caffeoylerigeroside and scutellarein-7-O- $\beta$-D-glucuronide) could be selected as potential chemotaxonomic markers of the genus Erigeron $\mathrm{L}$.
\end{abstract}

Keywords Asteraceae - Chemotaxonomy - Erigeron acris s. 1. P Phenolic compounds · Ultra high performance liquid chromatography

\section{Introduction}

The genus Erigeron L. (Asteraceae) comprises about 400 species and is closely related to genera Aphanostephus DC., Apopyros G. L., Conyza Less., Hysterionica Willd., and Neja D. Don. It is distributed mainly in temperate regions of North and South America and Eurasia (Noyes 2000; Nesom

Edyta Nalewajko-Sieliwoniuk nedyta@uwb.edu.pl

1 Department of Analytical Chemistry, Institute of Chemistry, University of Białystok, K. Ciołkowskiego $1 \mathrm{~K}$, 15-245 Białystok, Poland

2 Department of Taxonomy, Phytogeography and Palaeobotany, Institute of Botany, Faculty of Biology, Jagiellonian University, Gronostajowa 3, 30-387 Kraków, Poland

3 Department of Pharmacognosy, Medical University of Białystok, Mickiewicza 2a, 15-222 Białystok, Poland
2008). Erigeron acris L., commonly known as blue fleabane, belongs to Erigeron sect. Trimorpha (Cass.) DC. which is characterized by the presence of three types of flowers in each capitulum, namely female ligulate ray flowers, female eligulate ray flowers and bisexual disc flowers (Š́́da 1998). E. acris s. 1. is represented by annual, biennial and perennial plants and includes numerous subspecies in Europe and Asia (Halliday 1976; Greuter 2003; Pliszko 2015, 2016, 2018; Olander and Tyler 2017). The morphological variation of E. acris $\mathrm{s}$. 1. includes the size, the number and arrangement of capitula, the size and number of cauline leaves, as well as the indumentum of stem, leaves and involucral bracts (Šída 1998, 2000; Pliszko 2015, 2016, 2018; Pliszko and Kostrakiewicz-Gierałt 2018). Moreover, it is suggested that representatives of $E$. acris s. 1. can easily hybridize with each other or other closely related species such as E. canadensis L. and E. floribundus (Kunth) Sch. Bip. (Šída 2000; Pliszko 2015; Mundell 2016; Pliszko and Jaźwa 2017). Apart from the fact that the morphological variation within E. acris s. 1 . 
has been well documented (Pliszko 2015, 2016, 2018; Olander and Tyler 2017; Pliszko and Kostrakiewicz-Gierałt 2018), in terms of chemotaxonomy, it is completely neglected.

Considering the taxa included in E. acris s. 1., the examinations on chemical composition have been made only for E. acris subsp. acris (EAA) so far. The most important groups of chemical compounds recognized in this taxon are flavonoids, phenolic acid derivatives and polyacetylenic compounds (in essential oil) (Nazaruk 2006; Nazaruk et al. 2006; Nalewajko-Sieliwoniuk et al. 2008; Malejko et al. 2016, Nazaruk and Kalemba 2009). Phenolic compounds dominate in the aerial parts of E. acris subsp. acris but in the roots, they occur in small amounts. So far apigenin, luteolin, kaempferol, quercetin, luteolin 7-O-glucoside, quercetin 7-O-glucoside, scutellarein-7-O- $\beta$-D-glucuronide, erigeroside, 6'- $O$-caffeoylerigeroside, protocatechuic acid, caffeic acid, chlorogenic acid and 4,5-dicaffeoylquinic acid have been isolated from E. acris subsp. acris. Recognizing the chemical composition of taxa included in E. acris s. 1 . may allow their better use for phytotherapeutic purposes.

In Poland, E. acris s. 1. is represented by five taxa, namely E. acris subsp. acris, E. acris subsp. angulosus (Gaudin) Vacc., E. acris subsp. droebachiensis (O.F. Müll.) Arcang. (EAD), E. acris subsp. podolicus (Besser) Nyman, and E. acris subsp. serotinus (Weihe) Greuter (EAS) (Pliszko 2015, 2018; Nobis et al. 2019). Moreover, there is $E$. xhuelsenii Vatke (EH), a hybrid between the native E. acris subsp. acris and the invasive E. canadensis (Pliszko and Jaźwa 2017; Pliszko and Kostrakiewicz-Gierałt 2018). The above-mentioned taxa occur usually on dry mineral soils, in grasslands, on abandoned fields, in sand and limestone quarries as well as on roadsides and railway embankments (Pliszko 2015, 2018; Pliszko and Jaźwa 2017; Pliszko and Kostrakiewicz-Gierałt 2018; Nobis et al. 2019). E. acris subsp. angulosus is known from only one locality in northeastern Poland, E. acris subsp. podolicus is known only from one locality in southern Poland, whereas the other taxa are also rare in the country, except E. acris subsp. acris and E. acris subsp. serotinus (Pliszko 2015, 2018; Pliszko and Jaźwa 2017; Nobis et al. 2019).

The aim of this study was qualitative and quantitative analysis of phenolic compounds in the aerial parts of E. acris subsp. acris, E. acris subsp. droebachiensis, E. acris subsp. serotinus and $E$. $\times$ huelsenii. An ultra high performance liquid chromatography with photodiode array detection method (UHPLC-PDA) was used for the identification and determination of individual phenols in methanolic extracts from Erigeron acris s. 1. The chromatograms of the abovementioned taxa were compared and the potential marker compounds were suggested. Additionally, the total flavonoid and phenolic acid contents were determined by spectrophotometric methods. As far as we know, it is the first time when phenolic profiles and the content of plant phenols in extracts from $E$. acris subsp. droebachiensis, E. acris subsp. serotinus and $E$. $\times$ huelsenii have been investigated.

\section{Materials and methods}

\section{Reagents and solutions}

All chemicals were of analytical grade and solutions were prepared by using water purified in a Milli-Q Plus water purification system (Millipore S.A., Molsheim, France). Protocatechuic acid, chlorogenic acid, caffeic acid and quercetin were purchased from Sigma-Aldrich (Steinheim, Germany). 4,5-dicaffeoylquinic acid was obtained from MedChemExpress (Sollentuna, Sweden). 6'- $O$ caffeoylerigeroside, quercetin 3-O-glucoside, scutellarein-7$O$ - $\beta$-D-glucuronide and luteolin were isolated from E. acris (Nazaruk 2006; Nalewajko-Sieliwoniuk et al. 2008) in the laboratory of Department of Pharmacognosy, Medical University of Bialystok, Poland. The stock solutions of investigated phenolic compounds $\left(1000 \mu \mathrm{g} \mathrm{mL} \mathrm{m}^{-1}\right)$ were prepared in methanol (HPLC gradient grade, Sigma-Aldrich, Steinheim, Germany) and kept in the dark at $+4{ }^{\circ} \mathrm{C}$. The working solutions of analytes were prepared daily by an appropriate dilution of the stock solutions with a mixture of water:methanol (77:23, v:v). Hexamethylenetetramine, hyperoside and trifluoroacetic acid (HPLC grade) were supplied by SigmaAldrich (Steinheim, Germany). Sodium molybdate, sodium nitrate, acetone, ethyl acetate, hydrochloric acid, sodium hydroxide, sodium citrate, aluminum chloride and acetic acid were purchased from POCH (Gliwice, Poland).

\section{Plant material}

In this study we used the flower heads, leaves and herb (the above-ground morphological parts of the plant) of EAA and EAS, as well as the herb of EAD and EH collected by Artur Pliszko in Poland. EAA and EH were sampled from an abandoned sand and gravel pit located near the town of Suwałki, on 29 May 2014 and 7 August 2014, respectively (GPS coordinates: $54^{\circ} 04^{\prime} 11.64^{\prime \prime} \mathrm{N} / 22^{\circ} 58^{\prime} 5.88^{\prime \prime} \mathrm{E}$; altitude: $159 \mathrm{~m}$ ), EAD was sampled from a sandy grassland in the city of Toruń, on 18 July 2013 (GPS coordinates: 530.1'21.24"N/18³3'27.6" E; altitude: $47 \mathrm{~m}$ ), whereas EAS was sampled from an abandoned limestone quarry in the city of Kraków, on 24 July 2013 (GPS coordinates: $50^{\circ} 05^{\prime} 22.02^{\prime \prime} \mathrm{N} / 19^{\circ} 50^{\prime} 34.68^{\prime \prime} \mathrm{E}$; altitude: $239 \mathrm{~m}$ ). The plants were grown in sun-exposed places under temperate climate conditions. In Suwałki, Toruń, and Kraków the average annual air temperature is $6.4{ }^{\circ} \mathrm{C}, 7.9^{\circ} \mathrm{C}$, and $8.2{ }^{\circ} \mathrm{C}$, respectively, and average annual precipitation is $602 \mathrm{~mm}, 526 \mathrm{~mm}$, and $678 \mathrm{~mm}$, respectively (https://pl. climate-data.org). In case of rare taxa (EAD and EH) 30 individuals were sampled, whereas in case of frequent taxa 
(EAA and EAS) 50 individuals were sampled. All the aerial parts of the plants were collected at the stage of flowering and kept in a dark at room temperature for 7 days to dry. The voucher specimens were deposited at the Herbarium of the Institute of Botany of the Jagiellonian University in Kraków (KRA0497018-21). The taxa were identified by Artur Pliszko based on morphological features provided by Šída (2000).

\section{The total flavonoid content}

The total content of flavonoids was determined using the aluminium chloride colorimetric method described in Polish Pharmacopoeia XI, the monography of Solidaginis herba (2017). Dried and powdered herb, flower heads or leaves $(0.2 \mathrm{~g})$ were transferred to a round-bottom flask of $100 \mathrm{~mL}$. After that hexamethylenetetramine $(1 \mathrm{~mL}, 0.5 \%)$, acetone $(20 \mathrm{~mL})$ and $\mathrm{HCl}(2 \mathrm{~mL}, 25 \%)$ were added to the flask. The mixture was heated up in water bath, under reflux (30 min). Then the extract was filtered to a volumetric flask of $100 \mathrm{~mL}$ through a small wad of cotton. The residue of herbal extract and the cotton were resubmitted to reflux and re-extracted twice with acetone $(20 \mathrm{~mL})$ for $10 \mathrm{~min}$. After cooling and filtration, the extract was made up to $100 \mathrm{~mL}$ with acetone. This solution $(20 \mathrm{~mL})$ was mixed with water $(20 \mathrm{~mL})$ and then extracted four times with ethyl acetate (first with $15 \mathrm{~mL}$ and then three times with $10 \mathrm{~mL}$ ). Ethyl acetate extracts were rinsed twice with water, filtered and made up to $50 \mathrm{~mL}$ with ethyl acetate. $10 \mathrm{~mL}$ of the ethyl acetate extracts was mixed with $1 \mathrm{~mL}$ of an aluminium chloride reagent (2\%) and diluted with a $5 \%$ (v:v) solution of glacial acid in methanol to $25 \mathrm{~mL}$. The absorbance was measured at $425 \mathrm{~nm}$ after $30 \mathrm{~min}$ of incubation. This procedure was repeated six times for each part of the plant.

The total flavonoid content was calculated according to the following formula:

$(\%)=A \times 1.25 / m$,

the results were calculated as hyperoside, where $A$ is the absorbance of the examined solution at $425 \mathrm{~nm} ; m$ is the mass of the dry plant material in grams.

\section{The total phenolic acid content}

Dried and powdered herb, flower heads and leaves $(1 \mathrm{~g})$ were extracted twice with water ( $25 \mathrm{~mL}, 30 \mathrm{~min}$ for each extraction) at room temperature. After filtration, the extracts were transferred into a volumetric flask and made up to $50 \mathrm{~mL}$ with water.

The total phenolic acid content was determined by a spectrophotometric method utilizing Arnov's reagent described in Polish Pharmacopoeia VI, the monography of Taraxaci herba (2002). $1 \mathrm{~mL}$ of the extracts was mixed with $5 \mathrm{~mL}$ of water,
$1 \mathrm{~mL}$ of hydrochloric acid $(18 \mathrm{~g} / \mathrm{L}), 1 \mathrm{~mL}$ of Arnov's reagent ( $10 \mathrm{~g}$ of sodium molybdate and $10 \mathrm{~g}$ of sodium nitrate dissolved in $100 \mathrm{~mL}$ of methanol) and $1 \mathrm{~mL}$ of sodium hydroxide solution $(40 \mathrm{~g} / \mathrm{L})$ and made up to $10 \mathrm{~mL}$ with water. This procedure was repeated four times for each extract. The total phenolic acid content was calculated as caffeic acid percent using the following expression:

$(\%)=A \times 1.7544 / m$,

where $A$ is the absorbance of the examined solution at $490 \mathrm{~nm}$; $m$ is the mass of the dry plant material in grams.

\section{UHPLC-PDA analysis}

Dried and powdered herb, flower heads and leaves $(5 \mathrm{~g})$ were extracted under reflux $(1 \mathrm{~h})$, the first time with $200 \mathrm{~mL}$ and the second time with $100 \mathrm{~mL}$ of methanol. Then, the extracts were combined in a rotary evaporator Buchi R-215 Rotavapor System (Büchi, Switzerland) at $40^{\circ} \mathrm{C}$ under reduced pressure until dryness. The obtained yields of extraction of the aerial parts of EAA, EAD, EAS and EH calculated as percentage weight of the starting plant material $(\% w / w)$ were: EAA flower heads $-12.6 \%$, EAA leaves - $28.4 \%$, EAA herb $22.2 \%$, EAS flower heads $-22.6 \%$, EAS leaves $-34.8 \%$, EAS herb $-31.6 \%$, EAD herb $-28.4 \%$ and EH herb $25.6 \%$. After evaporation of solvent, the residues from herbs extract $(0.01 \mathrm{~g})$, leaves extract $(0.01 \mathrm{~g})$ and inflorescences extract $(0.02 \mathrm{~g})$ were re-dissolved in methanol $(5 \mathrm{~mL})$. Before UHPLC analysis, the extracts were diluted with water, in order to adjust the concentration of analytes to the linear calibration range, and filtered through a GHP syringe filter $(0.2 \mu \mathrm{m})$ (Waters Corp., USA). This procedure was repeated five times for each extract.

The qualitative and quantitative analysis of phenolic compounds were performed by ultra high performance liquid chromatography with photodiode array detection method (Malejko et al. 2016). An ultra performance liquid chromatograph ACQUITY UPLC $®$ H-Class with a photodiode array (PDA) $\mathrm{e} \lambda$ detector (Waters Corp., USA) was used throughout the study. The chromatographic separation was performed on Acquity UPLC BEH $\mathrm{C}_{18}$ column $(130 \AA, 1.7 \mu \mathrm{m}, 2.1 \mathrm{~mm} \times$ $50 \mathrm{~mm}$ ) equipped with Acquity UPLC Column In-line Filter $(0.2 \mu \mathrm{m}, 2.1 \mathrm{~mm})$ (Waters Corp., USA). The mobile phase was composed of solvent A: $0.02 \%(v / v)$ trifluoroacetic acid in water and solvent B: $0.02 \%(\mathrm{v} / \mathrm{v})$ trifluoroacetic acid in methanol. The following linear gradient profile was used: 0 min, $23 \%$ B; 8 min, $31 \%$ B; 12 min, $90 \%$ B; 13 min, $23 \%$ B. The injection volume was $2 \mu \mathrm{L}$ and the flow rate of the mobile phase was $0.4 \mathrm{~mL} / \mathrm{min}$. The column temperature was $25{ }^{\circ} \mathrm{C}$. The wavelengths used for the analysis of phenols by the UHPLC-PDA method were: $290 \mathrm{~nm}$ for protocatechuic acid, $330 \mathrm{~nm}$ for caffeic acid, chlorogenic acid, 6'-O- 
caffeoylerigeroside, 4,5-dicaffeoylquinic acid and scutellarein-7-O- $\beta$-D-glucuronide, $350 \mathrm{~nm}$ for luteolin and quercetin 3-O-glucoside, $370 \mathrm{~nm}$ for quercetin. The calibration graphs were linear in the range: $0.1-5 \mu \mathrm{g} \mathrm{mL} \mathrm{m}^{-1}$ (protocatechuic acid), $0.1-10 \mu \mathrm{g} \mathrm{mL}^{-1}$ (caffeic acid, quercetin), $0.1-20 \mu \mathrm{g} \mathrm{mL}^{-1}$ (chlorogenic acid, luteolin), 0.2$230 \mu \mathrm{g} \mathrm{mL}^{-1}$ (4,5-dicaffeoylquinic acid), $0.5-50 \mu \mathrm{g} \mathrm{mL}^{-1}$ (quercetin 3-O-glucoside, scutellarein-7-O- $\beta$-D-glucuronide, 6'-O-caffeoylerigeroside).

Waters Empower 3 software was used for the collection of chromatographic data, integration of chromatograms and evaluation of peak purity.

\section{Statistical analysis}

The software Microsoft Office Excel 2010 (Microsoft Corp, USA) was used for preparing the data analysis. The results were expressed as mean \pm standard deviation (SD). Outliers were eliminated from the dataset using the Q-test.

\section{Results and discussion}

The total contents of flavonoids and phenolic acids in the extracts from the aerial parts of EAA, EAD, EAS and EH were determined according to the procedures described in "The total flavonoid content" and "The total phenolic acid content" sections. The average values of determinations are shown in Table 1. In the case of EAA and EAS for which it was possible to collect a larger amount of raw material, the total contents of flavonoids and phenolic acids apart from the herbs were also determined in the extracts of flower heads and leaves of these plants. As it can be seen, the most abundant sources of phenolic acids were the leaves of EAA and EAS, while the highest concentration of flavonoids was observed in the flower heads of EAS. Regarding the content of phenolic acids and flavonoids in EAA and EAS, it could be concluded that higher

Table 1 Quantitative analysis of the total flavonoid and phenolic acid content in the aerial parts of EAA, EAD, EAS and EH

\begin{tabular}{lll}
\hline The source & $\begin{array}{l}\text { Total phenolic acid content } \\
\text { Mean } \pm \text { SD }[\%](n=4)\end{array}$ & $\begin{array}{l}\text { Total flavonoid content } \\
\text { Mean } \pm \text { SD }[\%](n=6)\end{array}$ \\
\hline EAA flower heads & $0.52 \pm 0.05$ & $0.66 \pm 0.12$ \\
EAA leaves & $1.34 \pm 0.09$ & $0.40 \pm 0.04$ \\
EAS flower heads & $0.86 \pm 0.07$ & $1.21 \pm 0.19$ \\
EAS leaves & $1.29 \pm 0.13$ & $0.73 \pm 0.01$ \\
EAA herb & $0.92 \pm 0.04$ & $0.62 \pm 0.02$ \\
EAS herb & $1.09 \pm 0.03$ & $0.59 \pm 0.02$ \\
EAD herb & $0.91 \pm 0.03$ & $0.51 \pm 0.09$ \\
EH herb & $1.06 \pm 0.04$ & $0.65 \pm 0.04$ \\
\hline
\end{tabular}

concentrations of phenolic acids were observed in the leaves than in the flower heads, whereas in the case of flavonoids, the flower heads contained higher concentrations of these compounds comparing to the leaves. Moreover, the herbs of all of the investigated taxa contained comparable amounts of phenolic acids (0.91-1.09\%) and flavonoids (0.51-0.65\%).

The UHPLC-PDA method was applied for the qualitative and quantitative analysis of phenolic compounds in methanolic extracts from E. acris s. 1. Nine compounds that had been identified and determined in our previous paper (Malejko et al. 2016) were also investigated in this study. The extracts were prepared according to the procedure described in "UHPLCPDA analysis" section. The chromatographic profiles of E. acris s. 1. extracts obtained by the UHPLC-PDA method are presented in Fig. 1a-d and Fig. 2a-d. The spectral characteristic of phenols and their retention times are presented in Table 2 . The chromatographic peaks were identified by comparing UV spectra and the retention times with those of pure standard solutions of phenols. Furthermore, the identification was also conducted by the addition of the corresponding standard phenolic solution to the sample which resulted in the increase in the surface area of a particular chromatographic peak. The average values of determinations of phenolic compounds in the aerial parts of EAA, EAD, EAS and EH performed by the UHPLC-PDA method are presented in Table 3 . As it can be seen, only methanolic extracts from the herb of EAA contained all examined phenolic compounds. The methanolic extracts from herbs of other investigated taxa were qualitatively poorer. The main substances determined in the tested herbal extracts were: scutellarein-7-O- $\beta$-D-glucuronide (EAA, EAS, EAD and EH), 6'-O-caffeoylerigeroside (EAA, $\mathrm{EAD}$ and $\mathrm{EH}$ ) and chlorogenic acid (EAS and $\mathrm{EH})$. The content of $6^{\prime}$-O-caffeoylerigeroside in the examined extracts from herbs was between $1.07 \pm 0.04 \mathrm{mg} \mathrm{g}^{-1}$ and $12.4 \pm 0.1 \mathrm{mg} \mathrm{g}^{-1}$ of dry weight of plant, the content of scutellarein-7-O- $\beta-\mathrm{D}-$ glucuronide fluctuated between $5.52 \pm 0.04 \mathrm{mg} \mathrm{g}^{-1}$ and 9.16 $\pm 0.3 \mathrm{mg} \mathrm{g}^{-1}$ of dry weight of plant, while the content of chlorogenic acid was in the range from $2.11 \pm 0.01 \mathrm{mg} \mathrm{g}^{-1}$ to $6.71 \pm 0.04 \mathrm{mg} \mathrm{g}^{-1}$ of dry weight of plant. Five of the nine tested compounds (chlorogenic acid, caffeic acid, 6'-Ocaffeoylerigeroside, scutellarein-7- $O-\beta-\mathrm{D}$-glucuronide and 4,5-dicaffeoylquinic acid) were found in all investigated extracts from herbs of E. acris s. 1. Caffeic acid, chlorogenic acid and 4,5-dicaffeoylquinic acid are wildly distributed in plants and therefore are inapplicable in chemotaxonomy (Böhm and Stuessy 2001; Chen et al. 2014). But 6'-O-caffeoylerigeroside and scutellarein-7-O- $\beta$-D-glucuronide are rather rare and they could play a role of a chemotaxonomic markers of the genus Erigeron (Zahoor et al. 2012 and references therein). 6'-Ocaffeoylerigeroside for the first time was isolated from E. multiradiatus (Lindl. ex DC.) Benth. ex C.B. Clarke (Zhang et al. 1998). Another derivative of erigeroside with caffeoyl moiety connected at C-3 position of glucopyranose 
Fig. 1 Chromatograms of methanolic extract from the herbs of EAA a, EAS b, EAD c, and EH d using UV absorbance detection at $330 \mathrm{~nm}$. Peaks: chlorogenic acid (1), caffeic acid (2), 6'-O-caffeoylerigeroside (3), scutellarein-7-O- $\beta$-Dglucuronide (4), quercetin 3- $O$ glucoside (5), 4,5dicaffeoylquinic acid (6), quercetin (7) and luteolin (8). The chromatographic conditions are detailed in "UHPLC-PDA analysis" section.
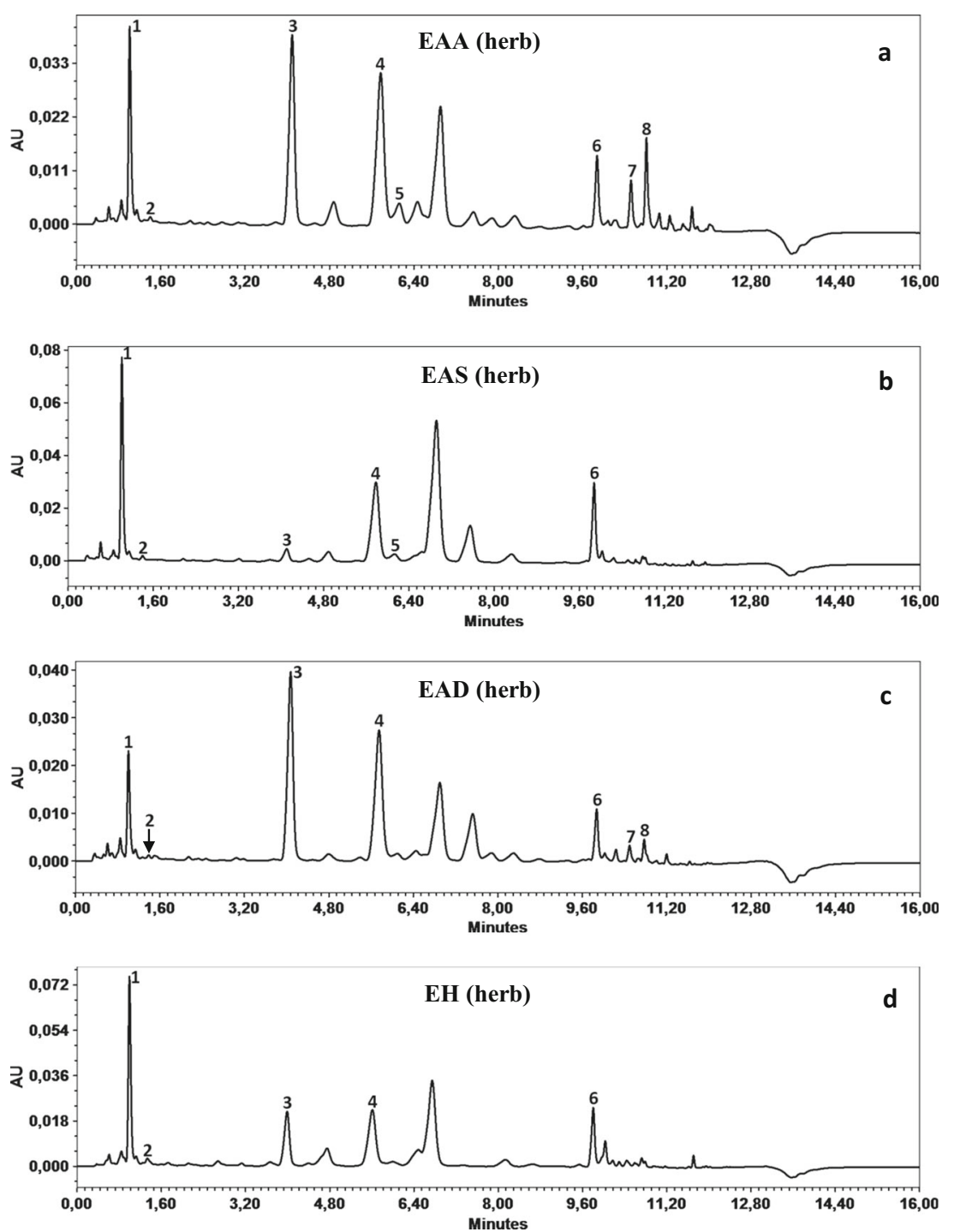

was isolated from the leaves of E. annuus (L.) Desf. (Hashidoko 1995). Pyromeconic acid derivatives seem to be significant in the genus Erigeron and they are rather rare in other genera; for instance, erigeroside was detected in Campylanthus glaber Benth. and C. salsoloides (L.f.) Roth from the family Plantaginaceae (Rønsted and Jensen 2002). Interestingly, after damaging the plant tissue, erigeroside hydrolyzed to the pyromeconic acid which demonstrated antifungal activity against plant pathogens (Hashidoko 1995). Scutellarein-7-O- $\beta$-D-glucuronide is the next important compound in the genus Erigeron. This compound was determined in a few species (e.g., E. acris and E. breviscapus (Vaniot) Hand.-Mazz.) (Hu et al. 2005; Zahoor et al. 2012) and can influence on the activity of these plants because it possesses broad spectrum of biological activities (Chledzik et al. 2018, Wang and Ma 2018). Scutellarein-7-O- $\beta$-D-glucuronide could be useful in curing cardiovascular diseases. Moreover, it could be an important antineurodegenerative, anti-
Helicobacter or anticancer drug, and is typed as one of the leading compounds in designing new multi-targeted therapeutic agents. Other phenolic compounds present in the studied plants are also very important secondary metabolites and have a wide variety of biological activities. The review of literature shows that 4,5-dicaffeoylquinic acid possesses potent hepatoprotective and anti-HBV effects (Hu et al. 2012). Moreover, it exhibits significant antitussive, expectorant and antiinflammatory activity (Wu et al. 2016). Chlorogenic acid possesses such properties as antioxidant (Kweon et al. 2001), antispasmodic (Farah et al. 2005), reduction of blood pressure, total cholesterol and LDL cholesterol (Wan et al. 2013), inhibition of the HIV-1 integrase (Kwon et al. 2000) and mutagenicity of the carcinogenic compounds (Farah et al. 2005). Caffeic acid has been reported to have the following biological activities: antioxidant (Maurya and Devasagayam 2010), antihypertensive (Hudson et al. 2000), antifibrosis (Park and Kahng 1995), antithrombosis (Johnson et al. 2010), antiviral 
Fig. 2 Chromatograms of methanolic extract from the leaves of EAA $\mathbf{a}$ and EAS $\mathbf{b}$ using UV absorbance detection at $290 \mathrm{~nm}$; and from the inflorescences of EAA $\mathbf{c}$ and EAS d using UV absorbance detection at $330 \mathrm{~nm}$. Peaks: chlorogenic acid (1), caffeic acid (2), 6'-Ocaffeoylerigeroside (3), scutellarein-7-O- $\beta$-Dglucuronide (4), quercetin 3-Oglucoside (5), 4,5-

dicaffeoylquinic acid (6), quercetin (7) and luteolin (8). The chromatographic conditions are detailed in "UHPLC-PDA analysis" section.
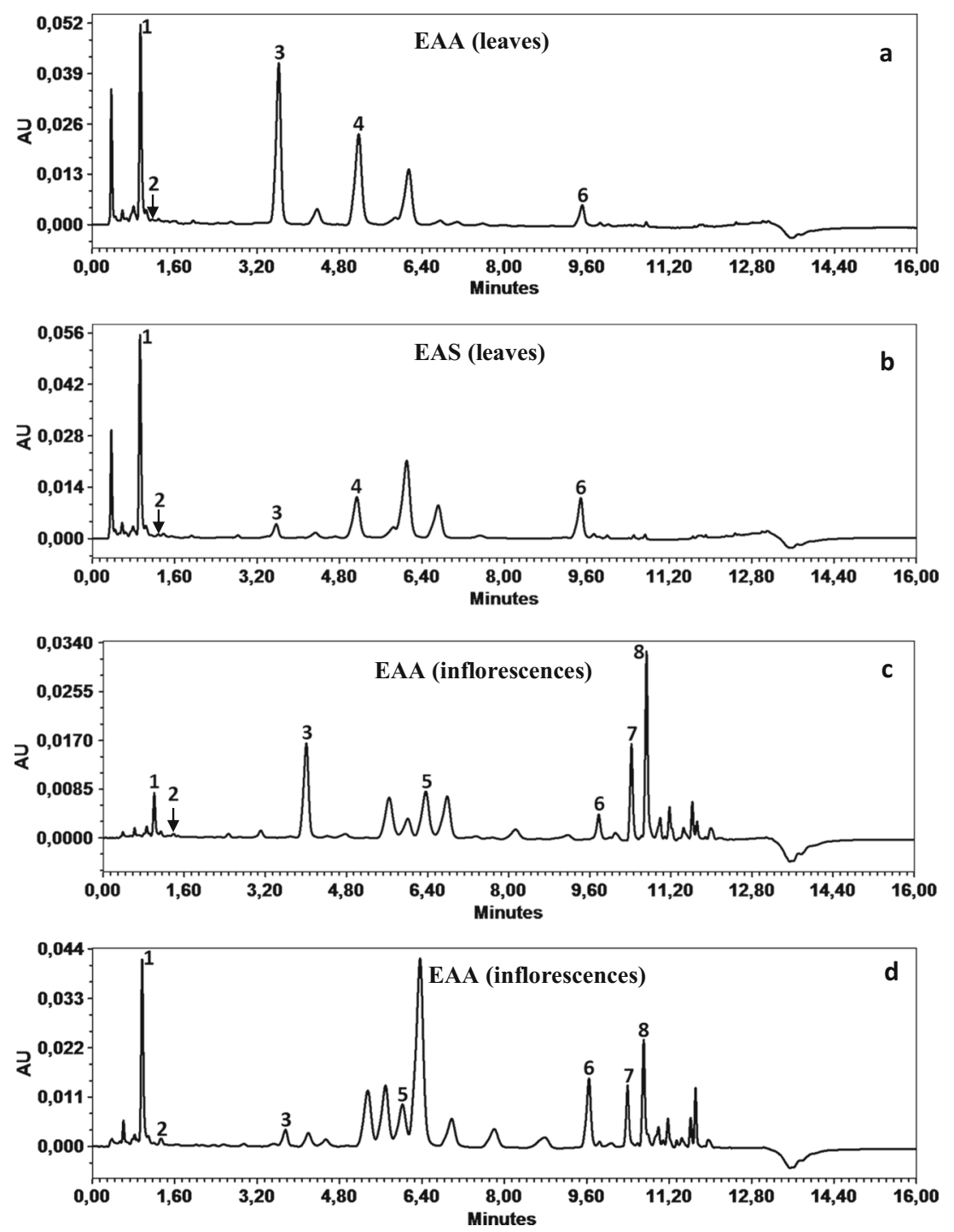

(Fesen et al. 1994) and antitumor (Morton et al. 2000). Protocatechuic acid possesses antioxidant, antihyperglycemic, anti-inflammatory, antimicrobial and anticancer activities (Semaming et al. 2015). Quercetin also possesses broad spectrum of biological properties including: anti-inflammatory, thrombosis, hypertension, arrhythmia and atherosclerosis as well as modulation of cancer-related multidrug resistance (Dajas 2012). Luteolin have been reported to possess antioxidant, antitumor, anti-allergic, antimicrobial, anti-inflammatory, reduced lipid accumulation and cardioprotective properties
Table 2 Phenols present in the extracts from E. acris s. 1 .

\begin{tabular}{llll}
\hline No. & Compound & Retention time[min] & UV absorption maxima[nm] \\
\hline 1. & Protocatechuic acid & 0.7 & $259 ; 294$ \\
2. & Chlorogenic acid & 1.0 & $241 ; 326$ \\
3. & Caffeic acid & 1.3 & 323 \\
4. & 6'-O-caffeoylerigeroside & 4.1 & $250 ; 327$ \\
5. & Scutellarein-7-O- $\beta$-D-glucuronide & 5.8 & $282 ; 334$ \\
6. & Quercetin 3-O-glucoside & 6.1 & $255 ; 354$ \\
7. & 4,5-dicaffeoylquinic acid & 9.8 & $244 ; 328$ \\
8. & Quercetin & 10.5 & $254 ; 371$ \\
9. & Luteolin & 10.8 & $254 ; 349$ \\
\hline
\end{tabular}


(Mahalapbutr et al. 2019). There are also other flavonoids, triterpenes, caffeoylic derivates, and steroids isolated from Erigeron species and some of them (e.g., benzyl O- $\beta$-Dglucopyranoside, 2 -phenylethyl- $\beta$-D-glucopyranoside and friedelin) seem to be common secondary metabolites in the genus Erigeron and other genera of Asteraceae (Zahoor et al. 2012 and references therein).

In the case of EAA and EAS the UHPLC-PDA method was also used to determine individual phenolic compounds in the extracts of flower heads and leaves of these plants. Based on the results presented in Table 3 it could be concluded that the leaves contained qualitatively less components than the inflorescences of EAA and EAS. Moreover, it was found that the inflorescences as well as the leaves of EAA and EAS contained the same phenolic compounds but in different quantities. The main components of methanolic extracts from flower heads were: quercetin 3-O-glucoside (EAA, EAS), quercetin (EAA, EAS), luteolin (EAA, EAS), 6'- $O$ caffeoylerigeroside (EAA) and chlorogenic acid (EAS). The main constituents of methanolic extracts from leaves were: scutellarein-7-O- $\beta$-D-glucuronide (EAA, EAS), chlorogenic acid (EAA, EAS), 6'-O-caffeoylerigeroside (EAA) and 4,5dicaffeoylquinic acid (EAS). Treating more critically the obtained results, it should be pointed out that the total content of phenolics and flavonoids not only depends on genetic differences between the taxa but also on growing conditions. It was evidenced by Albert et al. (2009) that temperature affects the phenolic composition in Arnica montana L. Similarly, Sytar et al. (2018) revealed that the temperature predominantly influences the accumulation of phenolic acids, whereas the level of UV radiation plays a dominant role in the accumulation of flavonoids in cultivars of Lactuca sativa var. crispa L. Moreover, Król et al. (2014) evidenced that drought stress causes reduction in total phenolic compounds in leaves and roots of Vitis vinifera $\mathrm{L}$. In this study, the taxa of E. acris $\mathrm{s}$. 1. were collected in different regions of Poland, in different habitats and in different time, following their flowering periods. These plants grew on different soils and before the sampling they were exposed to different weather. The abovementioned factors most likely influenced the content of phenolics in flower heads, leaves and herb of EAA and EAS as well as in herb of EAD and EH.

\section{Conclusions}

So far, very little has been done on the investigation of the composition and profiling of the plant phenolics in E. acris s. 1. To the best of our knowledge, in this study the total phenolic acids and flavonoids contents as well as profile of individual phenolic compounds in the aerial parts of EAD, EAS and EH have been determined for the first time. In the literature there is only one paper on the quantitative analysis of methanolic 
extracts from leaves and inflorescences of EAA prepared by ultrasound assisted extraction. Based on the obtained results, it can be concluded that the four investigated taxa differ in the composition and the content of phenolic compounds. However, five of the nine tested compounds were found in all extracts from herbs of $E$. acris s. 1. Moreover, two of them (6'-Ocaffeoylerigeroside and scutellarein-7-O- $\beta$-D-glucuronide) that are rare in plants are suggested as candidates for the chemotaxonomic markers of the genus Erigeron. The presence of phenolic antioxidants, such as protocatechuic acid, caffeic acid, chlorogenic acid, 4,5-dicaffeoylquinic acid, 6'-Ocaffeoylerigeroside, scutellarein-7-O- $\beta$-D-glucuronide, quercetin 3-O-glucoside, quercetin and luteolin in the aerial parts of the investigated taxa of $E$. acris s. 1. causes that they could be potentially employed as a natural source of biologically active compounds in cosmetics, medicine and pharmaceutical industry.

Acknowledgments We would like to thank the two anonymous Reviewers for their helpful and constructive comments that contributed to improving the final version of the manuscript. The equipment used in this work was partly supported by the EU funds [the project with contract number POPW.01.03.00-20-004/11]. Field surveys were financially supported by the Institute of Botany of the Jagiellonian University in Kraków [DS/MND/WBiNoZ/IB/4/2013].

\section{Compliance with ethical standards}

Conflict of interest The authors declare that they have no conflict of interest.

Open Access This article is distributed under the terms of the Creative Commons Attribution 4.0 International License (http:// creativecommons.org/licenses/by/4.0/), which permits unrestricted use, distribution, and reproduction in any medium, provided you give appropriate credit to the original author(s) and the source, provide a link to the Creative Commons license, and indicate if changes were made.

\section{References}

Albert A, Sareedenchai V, Heller W, Seidlitz HK, Zidorn C (2009) Temperature is the key to altitudinal variation of phenolics in Arnica montana L. cv. ARBO. Oecologia 160:1-8. https://doi.org/ 10.1007/s00442-009-1277-1

Böhm BA, Stuessy TF (2001) Flavonoids of the sunflower family (Asteraceae). Springer-Verlag, Wien

Chen J, Mangelinckx S, Ma L, Wang Z, Li W, De Kimpe N (2014) Caffeoylquinic acid derivatives isolated from the aerial parts of Gynura divaricata and their yeast $\alpha$-glucosidase and PTP1B inhibitory activity. Fitoterapia 99:1-6. https://doi.org/10.1016/j.fitote. 2014.08.015

Chledzik S, Strawa J, Matuszek K, Nazaruk J (2018) Pharmacological effects of scutellarin, an active component of genus Scutellaria and Erigeron: a systematic review. Am J Chin Med 46:319-337. https:// doi.org/10.1142/S0192415X18500167
Dajas F (2012) Life or death: neuroprotective and anticancer effects of quercetin. J Ethnopharmacol 143:383-396. https://doi.org/10.1016/ j.jep.2012.07.005

Farah A, De Paulis T, Trugo LC, Martin PR (2005) Effect of roasting on the formation of chlorogenic acid lactones in coffee. J Agric Food Chem 53:1505-1513. https://doi.org/10.1021/jf048701t

Fesen MR, Pommier Y, Leteurtre E, Hiroguchi S, Yung J, Kohn KW (1994) Inhibition of HIV-1 integrase by flavones, caffeic acid phenyl ester (CAPE), related compound. Biochem Pharmacol 3:595-608. https://doi.org/10.1016/0006-2952(94)90291-7

Greuter W (2003) The euro+med treatment of Astereae (Compositae) generic concepts and required new names. Willdenowia 33:45-47

Halliday G (1976) Erigeron. In: Tutin TG, Heywood VH, Burges NA, Moore DM, Valentine DH, Walters SM, Webb DA (eds) Flora Europaea vol. 4. Cambridge University Press, Cambridge, pp 116 120

Hashidoko Y (1995) Pyromeconic acid and its glucosidic derivatives from leaves of Erigeron annuus, and the siderophile activity of pyromeconic acid. Biosci Biotechnol Biochem 59:886-890. https://doi.org/10.1271/bbb.59.886

$\mathrm{Hu}$ Y-H, Zhang H, Zhang Z-F (2005) Determination flavonoids and scutellarin in herbs of Erigeron genus. Chin J Pharm Anal 25:21-23

Hu S-Q, Wu Y-H, Hao B-J, Lou J-D, Hu H-J, Zhang Y-Y, Zhao Y (2012) Evaluation of anti-apoptotic, anti-injury and antihepatitis B virus effects of isochlorogenic acid C in vitro. J Med Plant Res 6:31993206. https://doi.org/10.5897/JMPR11.1766

Hudson EA, Dinh PA, Kokubun T, Simmonds MS, Gescher A (2000) Characterization of potentially chemopreventive phenols in extracts of brown rice that inhibit the growth of human breast and colon cancer cells. Cancer Epidemiol Biomark Prev 9:1163-1170

Johnson AA, Marchand C, Pommery Y (2010) HIV-1 integrase inhibitors a decade of research and two drugs in clinical trial. Curr Top Med Chem 4:1059-1077. https://doi.org/10.2174/1568026043388394

Król A, Amarowicz R, Weidner S (2014) Changes in the composition of phenolic compounds and antioxidant properties of grapevine roots and leaves (Vitis vinifera L.) under continuous of long-term drought stress. Acta Physiol Plant 36:1491-1499. https://doi.org/10.1007/ s11738-014-1526-8

Kweon MH, Hwang HJ, Sung HC (2001) Identification andantioxidant activity of novel chlorogenic acid derivativesfrom bamboo (Phyllostachys edulis). J Agric Food Chem 49:4646-4655. https:// doi.org/10.1021/jf010514x

Kwon HC, Jung CM, Shin CG, Lee JK, Choi SU, Kim SY, Lee KR (2000) A new caffeoyl quinic acid from Aster scaber and its inhibitory activity against human immunodeficiency virus-1 (HIV-1) integrase. Chem Pharm Bull 48:1796-1798. https://doi.org/10. 1248/cpb.48.1796

Mahalapbutr P, Thitinanthavet K, Kedkham T, Nguyen H, Theu LTH, Dokmaisrijan S, Huynh L, Kungwan N, Rungrotmongkol T (2019) A theoretical study on the molecular encapsulation of luteolin and pinocembrin with various derivatized beta-cyclodextrins. J Mol Struct 1180:480-490. https://doi.org/10.1016/j. molstruc.2018.12.025

Malejko J, Nalewajko-Sieliwoniuk E, Szabuńko J, Nazaruk J (2016) Ultra-high performance liquid chromatography with photodiode array and chemiluminescence detection for the determination of polyphenolic antioxidants in Erigeron acris L. extracts. Phytochem Anal 27:277-283. https://doi.org/10.1002/pca.2626

Maurya DK, Devasagayam TP (2010) Antioxidant and prooxidant nature of hydroxycinnamic acid derivatives ferulic and caffeic acids. Food Chem Toxicol 48:3369-3373. https://doi.org/10.1016/j.fct.2010.09. 006

Morton LW, Croft KD, Puddey IB, Byrne L (2000) Phenolic acids protect low density lipoproteins from peroxynitrite-mediated modification in vitro. Redox Rep 5:124-125. https://doi.org/10.1179/ 135100000101535429 
Mundell ARG (2016) The genus Conyza in Britain and a name for the hybrid between Erigeron acris and Conyza foribunda (Asteraceae). New J Bot 6:16-20. https://doi.org/10.1080/20423489.2016. 1173806

Nalewajko-Sieliwoniuk E, Nazaruk J, Antypiuk E, Kojło A (2008) Determination of phenolic compounds and their antioxidant activity in Erigeron acris L. extracts and pharmaceutical formulation by flow injection analysis with inhibited chemiluminescent detection. J Pharm Biomed Anal 48:579-586. https://doi.org/10.1016/j.pba. 2008.05 .026

Nazaruk J (2006) Flavonoid aglycones and phytosterols from the Erigeron acris L. herb. Acta Pol Pharm 63:317-319

Nazaruk J, Kalemba D (2009) Chemical composition of the essential oils from the roots of Erigeron acris L. and Erigeron annuus (L.) Pers. Molecules 14:2458-2465. https://doi.org/10.3390/ molecules 14072458

Nazaruk J, Gudej J, Majda T, Góra J (2006) Investigation of the essential oil of Erigeron acris L. herb. J Essent Oil Res 18:88-90. https://doi. org/10.1080/10412905.2006.9699394

Nesom GL (2008) Classification of subtribe Conyzinae (Asteraceae: Astereae). Lundellia 11:8-38

Nobis M, Klichowska E, Terlević A, Wróbel A, Erst A, Hrivnák R, Ebel AL, Tikhomirov VN, Byalt VV, Gudkova PD, Király G, Kipriyanova LM, Olonova M, Piwowarczyk R, Pliszko A, Rosadziński S, Seregin AP, Honcharenko V, Marciniuk J, Marciniuk P, Oklejewicz K, Wolanin M, Batlai O, Bubíková K, Choi HJ, Dzhus MA, Kochjarová J, Molnár AV, Nobis A, Nowak A, Ot’ahel'ová H, Óvári M, Shimko II, Shukherdorj B, Sramkó G, Troshkina VI, Verkhozina AV, Wang W, Xiang K, Zykova EY (2019) Contribution to the flora of Asian and European countries: new national and regional vascular plant records, 8. Botany Letters. https://doi.org/10.1080/23818107.2019.1600165

Noyes R (2000) Biogeographical and evolutionary insights on Erigeron and allies (Asteraceae) from ITS sequence data. Plant Syst Evol 220: 93-114

Olander S, Tyler T (2017) Morphometrics and taxonomy of Erigeron acris sensu lato (Asteraceae) in Fennoscandia. New J Bot 7:3950. https://doi.org/10.1080/20423489.2017.1344076

Park EH, Kahng JH (1995) Suppressive effects propolis in rate adjuvant arthritis. Arch Pharm Res 22:554-558. https://doi.org/10.1007/ BF02975325

Pliszko A (2015) Taxonomic revision and distribution of Erigeron acris s. 1. (Asteraceae) in Poland. Phytotaxa 208:21-33. https://doi.org/10. 11646/phytotaxa.208.1.2

Pliszko A (2016) Erigeron acris subsp. baicalensis (Asteraceae), a new combination in Asian Erigeron. Acta Mus Siles Sci Natur 65:97100. https://doi.org/10.1515/cszma-2016-0012

Pliszko A (2018) Erigeron acris L. subsp. angulosus (Gaudin) Vacc. (Asteraceae), a new taxon in the flora of Poland. Acta Bot Croat 77:102-104. https://doi.org/10.1515/botcro-2017-0020
Pliszko A, Jaźwa M (2017) Floristic composition of vegetation in habitats suitable for Erigeron $\times$ huelsenii (Asteraceae). Acta Bot Croat 76:9 14. https://doi.org/10.1515/botcro-2016-0040

Pliszko A, Kostrakiewicz-Gierałt K (2018) The morphological intermediacy of Erigeron $\times$ huelsenii (Asteraceae), a hybrid between E. acris and E. canadensis. Turk J Bot 42:543-550. https://doi.org/10.3906/ bot-1711-27

Polish Pharmacopoeia VI. The Polish Pharmaceutical Society, Warsaw, 2002, pp 896

Polish Pharmacopoeia XI. The Polish pharmaceutical society, Warsaw, 2017, pp 1613-1614

Rønsted N, Jensen SR (2002) Iridoid glucosides and caffeoyl phenylethanoid glycosides from Campylanthus salsaloides and Campylanthus glaber. Biochem Syst Ecol 30:1091-1095. https:// doi.org/10.1016/S0305-1978(02)00061-3

Semaming Y, Pannengpetch P, Chattipakorn SC, Chattipakorn N (2015) Pharmacological properties of protocatechuic acid and its potential roles as complementary medicine. Evid Based Complement Alternat Med:1-11. https://doi.org/10.1155/2015/593902

Šída O (1998) Taxonomic problems in Erigeron sect. Trimorpha (Compositae) in Eurasia. Preslia 70:259-269

Šída O (2000) Erigeron acris agg. In the Czech Republic and Slovakia. Zprávy Čes Bot Společ 35:1-33

Sytar O, Zivcak M, Bruckova K, Brestic M, Hemmerich I, Rauh C, Simko I (2018) Shift in accumulation of flavonoids and phenolic acids in lettuce attributable to changes in ultraviolet radiation and temperature. SCi. Hortic 239:193-204

Wan CW, Wong CN, Pin WK, Wong MH, Kwok CY, Chan RY, Yu PH, Chan SW (2013) Chlorogenic acid exhibits cholesterol lowering and fatty liver attenuating properties by up-regulating the gene expression of PPAR-a in hypercholesterolemic rats induced with a highcholesterol diet. Phytother Res 27(4):545-551. https://doi.org/10. $1002 /$ ptr.4751

Wang L, Ma Q (2018) Clinical benefits and pharmacology of scutellarin: a comprehensive review. Pharmacol Ther 190:105-127. https://doi. org/10.1016/j.pharmthera.2018.05.006

Wu Q-Z, Zhao D-X, Xiang J, Zhang M, Zhang C-F, Xu X-H (2016) Antitussive, expectorant, and anti-inflammatory activities of four caffeoylquinic acids isolated from Tussilago farfara. Pharm Biol 54:1117-1124. https://doi.org/10.3109/13880209.2015.1075048

Zahoor A, Hussain H, Khan A, Ahmed I, Ahmad VU, Krohn K (2012) Chemical constituents from Erigeron bonariensis L. and their chemotaxonomic importance. Rec Nat Prod 6:376-380

Zhang Y, Li L, Yang P (1998) Isolation and structure of 6'-Ocaffeylerigeroside from Erigeron multiradiatus. Acta Pharm Sin 33:836-838. https://doi.org/10.1016/S0928-3420(99)80038-X

Publisher's note Springer Nature remains neutral with regard to jurisdictional claims in published maps and institutional affiliations. 